\title{
Learning architectures and negotiation of meaning in European trade unions
}

\author{
Linda Creanor ${ }^{\mathrm{a} *}$ and Steve Walker ${ }^{\mathrm{b}}$ \\ ${ }^{\mathrm{a}}$ Glasgow Caledonian University, UK; ${ }^{\mathrm{b}}$ Leeds Metropolitan University, UK
}

\begin{abstract}
As networked learning becomes familiar at all levels and in all sectors of education, cross-fertilisation of innovative methods can usefully inform the lifelong learning agenda. Development of the pedagogical architectures and social processes, which afford learning, is a major challenge for educators as they strive to address the varied needs of a wide range of learners. One area in which this challenge is taken very seriously is that of trade unions, where recent large-scale projects have aimed to address many of these issues at a European level. This paper describes one such project, which targeted not only online courses, but also the wider political potential of virtual communities of practice. By analysing findings in relation to Wenger's learning architecture, the paper investigates further the relationships between communities of practice and communities oflearners in the trade union context. The findings suggest that a focus on these relationships rather than on the technologies that support them should inform future developments.
\end{abstract}

\section{Introduction}

...learning - whateverformittakes - changeswhowe are by changing ourability to participate, to belong, to negotiate meaning. (Wenger, 1998, p. 226)

As we strive to come to terms with the possibilities of networked learning and its potential to afford a valuable, personalised learning experience for all participants, we become more aware of the variables that can influence the outcome (Creanor, 2002). Our perspective is strongly influenced by Jones (2004), who proposes the network metaphor as a means of unifying different aspects of research into advanced learning technologies based on computer networks. We see networked learning as a concept encompassing a range of online learning opportunities, many of which are gradually becoming familiar within educational practices at all levels, encouraged in the United Kingdom by government strategies and funding bodies (for example, Department for Education and Skills, 2005; Scottish Further and Higher Education Funding

\footnotetext{
* Corresponding author. Academic Practice Unit, Glasgow Caledonian University, 6 Rose Street, Glasgow G3 6RB, UK. Email: 1.creanor@gca.ac.uk
} 
Councils, 2003). In order to establish firmly the lifelong learning ethos, collaboration across traditional educational boundaries is encouraging an exchange of experiences and good practice between formal and less formal contexts, thus affording valuable insights into emerging practices and the design of the learning experience in a variety of situations.

One area where innovative methods are being trialled on a large scale is the trade union sector, where the lifelong learning agenda is being implemented in the United Kingdom via ambitious initiatives to raise skill levels and engage nontraditional learners in the workplace, underpinned by a major investment in online courses and the development of supportive environments (Creanor \& Walker, 2005). Across Europe also, federations are recognising the range of possibilities (Bridgford \& Stubbs, 2001) and pan-European collaboration, underpinned by appropriate communication tools, is opening up new opportunities for engaging members in trade union-related education and training. It has also raised the question of whether cooperation enhanced by online networks can afford more effective and timely responses to European-level industrial and political developments through active online communities. Emerging practice in this area is raising interesting issues in terms of the design and implementation of transnational online communities, whether for short-term online courses or to support those within specific industrial sectors whose interaction will evolve over longer periods. Emerging virtual communities such as these are referred to by Teigland and Wasko (2004) as electronic networks of practice, in which the mutual engagement associated with more traditional communities of practice $(\mathrm{CoPs})$ is supported among geographically distributed members in global organisations by communication technologies.

Wenger (1998) reminds us that learning cannot be designed, but merely facilitated or hindered by the processes and artefacts with which participants are expected to negotiate meaning. Nevertheless, he does concede the necessity of designing social infrastructures that will foster learning while simultaneously emphasising that a response to design is inevitably unpredictable, often giving rise to barriers and boundaries that may stifle rather than support engagement and identity. This paper will examine Wenger's proposed design for learning in relation to one particularly complex transnational online learning project in the trade union sector.

\section{Background}

The context of our paper is trade union education. While trade union education ${ }^{1}$ is primarily concerned with improving the capacity of trade unions to organise and represent workers, educational methods vary from context to context. One central debate in the design of learning situations has been the extent to which the tutor acts as a subject expert or a facilitator of learning (Miller \& Stirling, 1997). There is generally a strong commitment to active and participative learning that recognises learners as the experts in their own working contexts, as exemplified in the Swedish tradition of participative education and study circles. Study circles emphasise the relationship 
between learning and democracy, and there is no requirement for a study group leader to be a subject expert (Larsson, 2001). The pedagogy may vary, depending on the organisational and political contexts of the trade union. Miller and Stirling (1997) suggest that in contexts where unions need to emphasise the distinctiveness of their own positions, there may be a greater emphasis on expert-led education and the transmission of established union policies. More recently, as trade unions have started to explore online learning in a transnational context, a number of models have been implemented, including international study circles, which explicitly seek to adapt the dynamic of study circles to online learning by using information and communication technology (ICT) to connect local study groups (Salt, 2000); blended-mode learning combining face-to-face and distance learning phases (Creanor \& Walker, 2000) and larger-scale purely online workshops (Sawchuk et al., 2002).

As this paper will also demonstrate, new roles are emerging in response to innovative methods, including the concept of a proactive 'broker' who has the experience and skills to build bridges across cultural and organisational divides in support of mutual knowledge sharing and learning. The existence of alternative designs suggests the value of a framework within which these approaches can be located, potentially highlighting strengths and weaknesses in particular contexts to assist the design of future learning events. Such a framework may also suggest novel approaches.

\section{Learning architectures}

One potential starting point for considering a 'design space' for transnational trade union education is Wenger's (1998, pp. 231-236) discussion of learning architectures as a set of concepts, which can be applied to the design of a particular learning situation. Wenger proposes that the design of a learning situation confronts four fundamental issues-meaning, time, space and power-and that these can be captured through four corresponding dualities: participation versus reification, design versus emergence, local versus global and identification versus negotiability. These dualities are, in effect, axes that define the space in which learning design takes place. Wenger, of course, is centrally concerned with social learning within the framework of communities of practice. While trade union education is often centrally concerned with the practice(s) of trade unionism, it does not follow that all trade union education is conducted in the context of communities of practice.

The social perspectives of learning underpin Wenger's view of the gradual shaping of an individual's identity within a community. The ability to negotiate new meaning is inherent in the ability of the members to become involved in the interaction between participation and reification as practices emerge, stabilise and become accepted as legitimate processes. This is likely to involve boundary building as well as crossing, and convergence will only gradually be achieved through the evolution of individual expectations into the shared enterprise of the group. Wenger also proposes three modes of belonging, which he has identified as engagement 
(involvement in meaningful activities and interactions), imagination (exploration and risk-taking) and alignment (coordination of perspectives towards a common purpose).

This model is not, however, without its critics. For example, Schwen and Hara (2003) suggest that the CoP may be viewed as a metaphor for online design. Based on their analysis of four different types of CoPs within large organisations, they advise against the tendency to 'romanticise' online communities. They argue that Wenger's CoP design concept is no more than an idealised theoretical description, which requires to be legitimised by more robust research before it can be considered in any way prescriptive. Nevertheless, they do concede that it presents a 'provocative ideal', which is useful as a tool for dialogue rather than a blueprint for construction.

McNaught (2003) also highlights the need to find a balance between conflicting dimensions by working within what she terms the zone of effective change. She analyses this approach in the framework of polarity theory (Johnson, 1992), which addresses the implementation of innovation. McNaught re-interprets this in the context of innovative pedagogical methods with a specific focus on the re-use of learning resources. The general principles, however, are generic. The theory supposes that, by identifying the two extremes of a particular continuum, it should be possible to find a solution that accommodates both by focusing on the tensions between them. If we map this onto Wenger's four dimensions, the learning architecture appears to mirror the zone of effective change by recognising the polarities and explicitly incorporating them into the design process. Whereas Wenger's model identifies specific tensions within the learning design process, the polarity theory may be applied more flexibly as it recognises that these dimensions may change according to context. Nevertheless, the concept of tensions is clearly one that can be usefully applied to capture the many facets of learning design.

Similarly, Barab et al. (2003) have used Wenger's dualities model of learning architecture in discussing their design of a web-supported community of teachers. They add two more dualities, which they found helpful: a diversity/coherence dimension referring to the population of participants, and an online/face-to-face tension referring to modes of organisation of learning.

Within trade union education, there is currently some debate about the value of the concept of communities of practice. Some commentators have expressed concern that the increasing corporatisation of the concept in the world of knowledge management may render it insufficiently critical to realise value for trade unions (Sawchuk et al., 2002; Luton, 2003). The concept has, however, usefully been used in trade union education settings to explore learner participation in trade union education in (geographically) localised settings (Ball, 2003) and in considering the possible emergence of European transnational communities (Walker \& Creanor, 2000; Luton, 2003). While the critical edge of the CoP concept may have been diluted in discussions of workplace and vocational learning, concepts derived from communities of practice continue to have value in discussion of trade union education, as we hope to demonstrate in the following. 


\section{Project context}

Dialog On was a major project led by the European Trade Union College (ETUCO), the training agency of the European Trade Union Congress. The project lasted for just over two years, finishing in February 2004. The activities were organised around two major strands, each addressing aspects of the new economy and its implications for trade unions:

- a 'networking' strand supporting cross-border sectoral trade union networking activities; and

- a computer-mediated distance learning (CMDL) strand developing models of cross-border trade union education.

Within these two strands, a total of 13 trade union organisations led activities with central project support organised by ETUCO along with staff from two trade union confederations and Glasgow Caledonian University. The support comprised a training programme for each strand. The CMDL training prepared experienced trade union educators from the confederations to design and deliver blended mode, national and transnational courses. The networking training prepared 'animateurs' from the various sectoral union federations to lead the creation of online networks of various types. Two animateurs were trained for each network, one primarily with organisational/political responsibility for the network and one with more operational/ pedagogic responsibility. The training was supported with a set of training materials, which were also available for 'downstream' courses and activities. A common technical platform (First Class) was available to underpin all activities, along with technical, organisational and administrative support provided by ETUCO.

Given the rich and complex environment that provided the backdrop for the Dialog On project, it was inevitable that certain challenges would be fore-grounded. For example:

- Historically the trade union movement has relied on face-to-face meetings and the spoken word, with great value placed on the ability to negotiate agreements through political astuteness combined with verbal dexterity. Transferring this to an online, text-based environment where communication is more one-dimensional is a major shift of emphasis.

- An existing sense of trust and identity with the trade union culture is key to its prime aim of solidarity. Capturing this notion of belonging is crucial to engaging members in the virtual world. The highly political nature of some aspects of trade union culture can, however, serve to undermine this sense of trust.

- The democratic processes on which the trade union movement is founded may be helped or hindered by the design of the learning environment.

- Shifting from a national to a transnational focus is likely to heighten the tensions between local and global interests.

Negotiation of meaning and convergence of what Wenger describes as 'diverse knowledgeabilities' (1998, p. 247) towards a shared vision involves accepting, assimilating and overcoming challenges as they emerge in response to, or even in spite 
of, the learning design. It was hoped to capture a wide range of these variables through the project evaluation.

\section{Evaluation methodology}

The evaluation was designed primarily for an internal project audience, seeking to contribute to the development of practice among trade union educators and trade unionists more widely. The evaluation design drew on structuration theory (Giddens, 1984), largely as developed in the information systems field by Orlikowski (1992, 2000). Structuration theory seeks to overcome the historic division in the social sciences between those accounts that see human behaviour as being largely determined by broader structural forces and those that conceive of human agency purely in terms of subjective interpretations. Structuration theory provided a 'sensitising device' (Giddens, 1984) to consideration of the relationship between broader social structures (including technology use) and the actions and interpretations of the people involved, both as tutors and learners. Structurational approaches to studying the use of information technology have also yielded more specific concepts such as communicative genres (Orlikowski \& Yates, 1994) and technology use mediation (Orlikowski et al., 1995), which have been used in identifying key aspects of the project.

The evaluation was conducted as a series of comparative case studies of eight 'networks' and eight CMDL courses. Within each case, data were gathered by analysis of content (focusing on the emergence of recurrent communication practices and genres as indicators of communication behaviour) and levels of online messages; semistructured interviews with network 'animateurs', pre-participant and post-participant/ learner questionnaires, and participation of animateurs, trainers and evaluators in a project-end evaluation workshop.

\section{Two case studies}

The cases outlined in the following are examples of the two major strands of activity within the project. Case $\mathrm{A}$ is an example of a transnational computer-mediated distance learning course that aimed to bring together (both physically and virtually) learners from two countries for a specified period to work and learn together around issues of common concern. Case B is an example of a 'networking' activity in which an educational intervention was designed to establish a broader ICT-mediated network of trade unionists with a view to extending their collaborative activities, encouraging cross-cultural exchanges and strengthening their political influence. A short overview of each case is given, followed by a comparative discussion organised around Wenger's (1998) four dualities.

\section{Case A overview: distance learning course}

This distance learning course brought together 16 members of trade unions representing professional staff in Italy and France to examine the situation of those staff in 
the two countries, in the context of globalisation, as well as technological and organisational innovation. In particular, the course aimed to strengthen the role of the union and to identify issues for negotiation by trade unions in the area of training and professional competences. The course was organised as a five-day residential workshop, followed by a three-month distance learning phase, and a concluding three-day residential workshop. Two experienced trade union educators led the first residential workshop, with invited experts introducing particular themes to the course participants. The distance phase had three subphases: an introduction in which people downloaded a template with which to present a short profile of themselves and the trade union context in which they were employed; working collaboratively to produce a document identifying and describing potential tools for the recognition of potential competences and measuring their value; and working collaboratively to produce a document discussing possible levels of union intervention. The second and third of these subphases were conducted in three working groups-one made up of French participants, one of Italian participants and a joint group with a specific mandate to explore the issues at a European level. At the second residential workshop, participants presented the results of their work, debated the analyses and evaluated the role of ICT in the course.

\section{Case B overview: sectoral network}

This case concerns the establishment of a network of trade unionists concerned with European Works Councils (EWCs) ${ }^{2}$ in the transport sector. The network aimed to include trade union members of EWCs, officials of national unions with responsibilities for working with EWCs, and members of the relevant European Industry Federation's (the European Transport Workers' Federation) executive committee. During the project, the network grew to include 40 members, of whom 16 also took part in the residential workshops. Participants came from at least seven countries across Europe, although a low response rate to the participant profile questionnaire means that this is almost certainly an underestimate. During the life of the project, 25 network members posted at least one message in the conference. Participants included a diverse mixture of elected representatives at various levels of the trade union organisation, EWC members and trade union employees. The objectives of the network, from the perspective of the European federation, were to collect and share information between EWCs and union officials, improve communications within and between EWCs, discuss and develop strategy for EWCs within the sector, and discuss and develop the role of EWC coordinators. Two members of the group took on the role of facilitators or 'animateurs' of the network with the aim of encouraging participation and knowledge sharing. One of these, an experienced EWC member, took part in the project's 'animateur' training for those responsible for leading the work of the networks. The second 'animateur' for the network withdrew from the training although he acted as a trainer/workshop leader for the two subsequent residential workshops. The format of combined residential and online phases was similar to that of case study A, although from its inception a longer lifespan was envisaged for the 
network. The first of the two workshops provided an opportunity to prepare objectives and strategy for the network, exchange information and establish jointly agreed guidelines. The strategic aspects of the workshop built on an earlier event, organised outside the framework of the project. The second workshop was held five months later and aimed to evaluate the work of the network to that point and consider plans for future development.

Following the first workshop, the electronic network was launched with a preliminary work programme of collecting information on well-established EWCs in the industry in preparation for a conference bringing them together. Ground rules for online working were established, including a commitment of participants to log on at least weekly and an agreement to welcome new members in to the network, although training in the network technology could only be offered to participants in the preproject workshop. Although the 'animateur' would take overall responsibility for facilitating the online group and organising its tasks and resources, it was expected that members would also provide mutual support. Timescales for the completion of the tasks were not published and little was communicated in direct relation to the task online between the two workshops. Almost one-half $(47 \%)$ of all messages were posted by just two participants, as the network adopted a predominantly informationdissemination pattern of communications. The second workshop agreed to continue the online network and to establish a second subconference, particularly for an industrial subsector where language was expected to be less of a barrier to communications, although this was not done during the life of the project.

\section{Dialog On in four dimensions}

\section{Participation and reification}

Wenger argues that participation and reification are central dimensions of practice and identity. Participation refers to the experiences of active involvement and membership of communities of practices, and reification to the tools or 'things' that facilitate them.

The residential workshops organised through the project gave both cases the opportunity for face-to-face encounters and participation. In Case B, these took place to some extent in the context of other events outside the project itself, which brought together at least some network members as part of an ongoing practice. However, the use of online conferencing changes the relationship of participation and reificationthe very use of online text-based conferencing systems collapses aspects of the relationship between participation and reification. In using the medium, participation by posting online immediately reifies the communications as stored text. Legitimated communication structures are also reified through the very structure of the conferencing software, which supports particular ways of organising messages and responses (threading) and the use of (in the context of First Class) subconferences, subfolders and file attachments. The design, by the tutors, of the conference space concretises certain patterns of participation. In Case A, tutors established specific subconferences 
in the main course conference for the three online working groups. Similarly, in Case $\mathrm{B}$ a subconference was established for discussions relating to the establishment of a particular EWC, along with subfolders intended to contain supporting documentation to the work of the network.

The organisation of the two activities differed in the extent to which the outcomes of online working were realised. In Case A, working groups organised their collaboration around the production of documents as outputs: typically, word-processed reports or presentations designed to support face-to-face presentations at the second workshop. While documents of various forms were circulated in the conferences of Case B, they were not used specifically as the outcome of particular tasks.

A further consequence of the reification of communications reported across the project related to the use of second or third languages. Some participants reported that while their spoken/aural skills in their second or third language were adequate, their written skills were less developed, particularly where language skills had been developed informally. Posting messages in the networks was more time-consuming and also more intimidating in that a permanent record is bearing witness to linguistic mistakes. The 'animateur' of one network speculated further that this was a particular problem for trade union officials for whom dealing in subtle shades of meaning is a widespread concern.

\section{Designed and emergent}

According to Wenger, communities' practices are highly emergent and frequently improvised, concerned primarily with getting something done. These practices cannot themselves be designed, but are better thought of as a response to design. Learning interventions therefore create a tension between the emergent practices of a community and the design of the learning. Different approaches to the design of learning might seek to promote or inhibit the emergence of particular ways of doing things, but cannot ultimately guarantee that they will be achieved. The interaction between the designed and emergent, however, provides impetus to the process of negotiation of meaning.

The project proposal pre-defined some elements of the learning activities, most clearly in specifying the mix of face-to-face and online episodes. The project also provided central support both of educators and those taking on 'animation' responsibilities, a core element of which were training courses for the two functions, themselves organised in a blended approach to give the tutors and 'animateurs' an experience similar to that of the users. The tutors in the distance learning strand were then responsible for the design of the residential and online phases of the course, as already outlined for Case A. Two specific examples, however, illustrate the extent to which the design was flexible. First, for logistical reasons it proved impossible to provide training in the conferencing platform at the first residential workshop. This was less of a problem for the Italian participants, who already had experience because their own trade union confederations used the same system. The French participants, however, had not previously used the system and preferred to organise their 
substantive work via email. Second, as it became clear that the course participants were taking longer to complete the tasks than the tutors had originally envisaged, a fourth subphase was abandoned.

It is clear that in Case A online activities were more explicitly designed by the tutors to achieve particular learning outcomes: each task had a specific output and associated timescale (although this was open to negotiation). The online activities in Case B were less explicitly designed. The major focus of online working was not the task agreed at the workshop. The network was used, for example to disseminate information about the establishment of a particular EWC and was used extensively in circulating information during a relatively short-lived industrial dispute. It was also used to circulate information about relevant events. The inherent flexibility favoured emergence, thus minimising the impact of the learning design and maximising opportunities for negotiation of meaning.

\section{Local and global}

All practices, whatever their geographic scope, are, in Wenger's terms, local practices. These local practices are affected in learning situations by inputs from other, equally local, neighbouring practices in wider networks of practice. In designed learning situations, a key neighbouring community to that of the learners will be that of the educators, giving rise to what Fowler and Mayes (1999) have identified as 'first order' learning relationships. Central to the learning interventions discussed here, the participants are simultaneously members of local (in a geographic sense) communities of practice and the learning communities constituted in the courses and networks. The courses have been designed specifically to assist participants to learn from the other course participants and to incorporate new ideas and methods into the work of their geographically local community of practices.

The core concern of the project methodology was the establishment of working methods among geographically widespread trade unionists in Case A between two countries and in Case B, potentially at least, across the European Union. The residential workshops in both cases provide opportunities for local encounters: the essential difficulty in both has been in sustaining interaction at a distance. This may be for a number of reasons. One difficulty is competing demands on time. A common occurrence throughout the project has been participants' apologising for being unable to sustain involvement in online activities when other, geographically local, demands are competing. It may be a particular feature of trade unionism that the work is reactive to external events, as issues arise in the workplace or at the policy level. In the face of the demands that these have placed on participants' time, it has proved difficult for many to sustain their involvement. Time factors may also have had an effect on other dimensions, particularly in relation to the impact on emergent practices. However, as noted by Teigland and Wasko (2004, p. 239), level of participation in the network is more significant than the length of time over which individuals participate. In these cases, neither the level nor length of participation was easily sustained. 
Furthermore, the extended geographic scope of the project is also closely associated with language, the major difficulty in both of these situations. In face-to-face workshops, this was addressed by providing simultaneous translation, at least in the formal sessions. In Case A this meant that, subject to the restrictions of simultaneous translation, all participants could take part in their mother tongue. In Case B translation could not be provided in language pairs, resulting in some participants working in a second or third language.

\section{Identification and negotiability}

When learning interventions are designed they 'place a stake in the ground' (Wenger 1998, p. 235), focusing participant identification and making a bid for the ownership of meaning. Design may allow for and encourage the negotiation of meaning, or it may attempt to restrict it. In different approaches to learning, the meaning of a particular event may be more or less open to negotiation between designers and participants. In the case of trade union education, there is typically a relatively open approach to the negotiation of meaning between tutors and learners.

In both of the cases here, participation itself can be taken as an indicator of individual identification at some level as trade unionists. Identification, which is at the core of Wenger's view of learning, is, however, limited in a number of ways. In Case A, the course is time limited, which itself is likely to constrain a sense of identification with the course and other participants. One participant commented in a conference contribution that it felt as if the end of the course had blocked the work 'en route' to successful completion. When asked whether they expected to continue working with other course participants following the course, all of the respondents (7/16 participants) either agreed or agreed strongly that they expected to continue working with participants from their own country; one-half of the respondents (4/7) agreed that they would continue working with colleagues from the other country, the remainder being 'unsure'. Reasons for the difference between participants' expectations of working with fellow nationals and partner nationals may be attributable to a number of factors potentially including difficulties in developing shared senses of belonging, exacerbated by language difficulties and organisation of learning (the majority of participants working in separate, linguistically based groups during the online phase), and/or recognition of the different national contexts of trade union work and recognition of the logistical difficulties of sustaining future collaboration.

In Case $\mathrm{B}$, there is a more ambitious attempt to create a social formation that might look rather more like a community of practice in which group members provide mutual support and share goals. For example, the two residential workshops expressed a concern to help new members come in to the network, recognising the need to encourage and legitimate such 'novice' participation. Participation in the network, at least initially, was an indication of commitment to the development of a practice of trade unionism in EWCs. However, some network members expressed a concern that involvement in the network was not sufficiently helpful in supporting 
participants' involvements in other areas of (perhaps communities of) practice, such as their involvement in their own EWCs.

\section{Discussion}

The Dialog On activities described appear to indicate that Wenger's learning architecture should be seen as informative, rather than prescriptive, in relation to developments in this sector. The tensions that emerged during the establishment and implementation of the learning communities and the online networks confirm that the dualities should be acknowledged and addressed directly if potential problem areas are to be designed out at an early stage. For example, had the initial training interventions for the online facilitators in both strands included more comprehensive guidance on managing language issues, communication and participation may have been more productive for many of the groups. This explicit emphasis on communication, language and culture would impact on an individual's identification with and sense of belonging to the group, thus encouraging progress towards convergence and common goals. The highly prized 'mutual knowledgeability' becomes much more difficult to attain when nuances of meaning and cross-cultural misunderstandings interrupt the reciprocal flow of information.

In terms of the four dimensions, therefore, these cases highlight the role not only of learning design and its limitations in influencing emergent practices, but also the potential role of the tutor or 'animateur' as a broker of diverse knowledgeabilities across cultural and organisational boundaries in a constellation of European trade union practices. The outcomes suggest that while an awareness of the dimensions is undoubtedly helpful in designing a learning intervention and preparing for these key roles, the inherent challenges of facilitating online interaction across borders demand thorough preparation and an ability to incorporate a greater degree of flexibility than the model suggests.

The modes of belonging can also inform design. For example, identity is seen as the 'vehicle that carries our experiences from context to context' (Wenger, 1998, p. 268). If, as Wenger suggests, the traditional classroom is too disconnected from the world and too uniform to support meaningful forms of identification, how can the online environment be designed in order to afford the boundary spanning that is essential to the expansion of the trade union influence in Europe? Participant profiles demonstrated that those taking part in the online activities were active trade unionists, with many in a position to exert a strong influence on developments at a national and a transnational level. Informal feedback indicated that their experience within the project is likely to have an impact on their work at a (geographically) local level. In Dialog On the objective was not explicitly designed into the learning process (although there is an implicit assumption in most trade union education that trade union practices will be strengthened through education), but by encouraging more explicitly the transfer of boundary objects to other communities, both real and virtual, via the multi-membership of individual participants, trade union influence can be usefully strengthened. In this scenario, the brokering role of the tutor/animateur 
exerts a major influence. By re-visiting the levels of participation and access to the online communities, for example by allowing peripheral involvement via 'read-only' access to conferences, as happened in at least one of the networks, the involvement and interest of a wider trade union audience could be encouraged and democratic and participative traditions addressed.

\section{Conclusion}

Wenger's learning architecture has been derived from the study of CoPs, but our evidence also suggests that sustainable 'networks' can be nurtured and encouraged as a positive outcome from the kind of short-term learning communities established in the project's CMDL strand. This longer term collaboration can be encouraged and informed by the pedagogical practices, social processes and roles established within the online courses. Further research is needed to test this hypothesis but, if it is found to be a useful method to enhance the reach and influence of trade unions in Europe, it has significant implications for training interventions and learning design. It also reinforces the fact that networked learning and the more broadly defined communities of practice are closely related, and that, as Jones (2004) proposes, a range of interdisciplinary perspectives should be considered when examining the impact of online collaboration.

Other areas that merit further investigation beyond this particular sector include:

- Designing for emergence - how can we reconcile the tension between developing practices within a community and the learning design? Given the current emphasis on artefacts (learning objects), associated activities and the standards agenda, this would appear to be a fundamental issue. In the specific context of trade union education, the maturity and expertise of participants offers particular opportunities for explicitly linking online pedagogies to the emergence of novel external practices.

- Boundary crossing - in complex transnational contexts, how can learning design support alignment between the often diverse local (national and organisational) priorities as well as the broader, global imperatives that communities such as these are invited to engage with?

- Participation and reification online - we know that different communication modes reify participation in different ways (e.g. the text record in an online conference is a very different type of reification from that of minutes produced after a formal meeting). So what is the impact of the design of the virtual learning space, in particular the organisation, facilitation and management of online discussions, on the relationship between these dualities?

Wenger's learning architecture is clearly not definitive. If it is to inform the design for learning and, by extension, the longer term sustainability of effective communities, it should be viewed flexibly. Acknowledging and valuing the inevitable polarities and explicitly addressing them within the training interventions can make negotiation of meaning within and across complex boundaries more attainable and meaningful. 
Communication technologies are vital to the future development of transnational collaboration but, rather than experimenting with cutting edge tools, we would argue that the focus should be on the nuances of interaction, the role of the 'broker' and the impact of design. If the development of online learning and CoPs in the trade union sector is to be encouraged, continuing investigation of the emerging pedagogical and social processes, and the relationships between them, is essential.

\section{Acknowledgements}

The Dialog On project was supported by the European Social Fund, Innovative Measures, from November 2001 to February 2004. An earlier version of this paper was presented at ALT-C 2004, where it won a research paper award.

\section{Notes}

1. In a trade union context, the terms education, training and skills development are used interchangeably (Miller \& Stirling, 1997).

2. Since the 1990s, European Union legislation requires all companies employing more than 1000 people and operating in more than one member state to establish a EWC as a forum for sharing information and consulting with employee representatives. EWCs have represented a major new area of work for European trade unions. Coordination of trade union involvement in establishing and participating in EWCs is a task of the European trade union federations (European Industry Federations), which bring together the national trade unions that organise in a particular industrial sector.

\section{References}

Ball, M. (2003) Considering trade union education as a community of practice, International fournal of Lifelong Learning, 22(3), 297-310.

Barab, S. MaKinster, G. \& Scheckler, R. (2003) Designing system dualities: characterizing a websupported professional development community, The Information Society, 19, 237-256.

Bridgford, J. \& Stubbs, D. (2001) European trade union distance education: first ETUCO experiences, in: E. Gabaglio \& R. Hoffman (Eds) European trade union yearbook (Brussels, ETUI).

Creanor L. (2002) A tale of two courses: a comparative study of tutoring online, Open Learning, $17,57-68$.

Creanor, L. \& Walker, S. (2000) European trade union distance education, Educational Media International, 37(4), 263-269.

Creanor, L \& Walker, S. (2005) How trade unions are using (and supporting) ICTs to Deliver Learning. Report commissioned by Trades Union Congress, London. Available online at: http:// www.learningservices.org.uk/national/learning-4014-fo-cfm (accessed 12 May 2005).

Department for Education and Skills (2003) E-strategy. Available online at: http:// www.dfes.gov.uk/publications/e-strategy (accessed 12 May 2005).

Fowler, C. J. H. \& Mayes, J. T. (1999) Learning relationships: from theory to design, Association for Learning Technology fournal, 7(3), 6-16.

Giddens, A. (1984) The constitution of society (Cambridge, Polity Press).

Johnson, B. (1992) Polarity management: identifying and managing unsolvable problems (Amherst, MA, HRD Press). 
Jones. C. (2004) Networks and learning: communities, practices and the metaphor of networks, ALT-f, 12, 81-93.

Larsson, S. (2001) Seven aspects of democracy as related to study circles, International fournal of Lifelong Learning, 20(3), 199-217.

Luton, G. (2003) Worker representative training in Europe: are there lessons for social responsibility?, paper presented to the seminar Responsible Restructuring in Europe, Dublin, 19-20 June. Available online at: http://www.responsible-restructuring.org/fr/pdf/Luton-final-text.pdf (accessed 12 May 2005).

McNaught, C. (2003) Identifying the complexity of factors in the sharing and re-use of resources, in: A. Littlejohn (Ed.) Reusing online resources: a sustainable approach to e-learning (London, Kogan Page), 199-211.

Miller, D. \& Stirling J. (1997) Trade union education in Europe: a pilot study (Dusseldorf, Hans Bockler Foundation).

Orlikowski W. (1992) The duality of technology: rethinking the concept of technology in organizations, Organization Science, 3(3), 398-427.

Orlikowski, W. (2000) Using technology and constituting structures: a practice lens for studying technology in organizations, Organization Science, 11(4), 404-428.

Orlikowski, W. \& Yates, J. (1994) Genre repertoire: the structuring of communicative practices in organizations, Administrative Science Quarterly, 39, 541-574.

Orlikowski, W., Yates, J., Okamura, K. \& Fujimoto, M. (1995) Shaping electronic communication: the metastructuring of technology in the context of use, Organization Science, 6, 423-444.

Salt, B. (2000) International study circles, Information, Communication E Society, 3(3), 337-346.

Sawchuk, P. H., Gawron, Z. \& Taylor, J. (2002) E-learning and union mobilization, fournal of Distance Education/Revue De L'educations a Distance, 17(3), 80-95.

Schwen T. M. \& Hara N. (2003) Community of practice: a metaphor for online design? The Information Society, 19, 257-270.

Scottish Further and Higher Education Funding Councils (2003) SFEFC/SHEFC joint e-learning report. Available online at: http://www.sfc.ac.uk/joint_info/publications/joint_e-learning report_july_2003.pdf (accessed 12 May 2005).

Teigland, R. \& Wasko, M. (2004) Extending richness with reach: participation and knowledge exchange in electronic networks of practice, in: P. Hildreth \& C. Kimble (Eds) Knowledge networks: innovations through communities of practice (Hershey, PA, Idea Group), 230-242.

Walker, S. \& Creanor, L. (2000) European trade union distance education: potential and problems, paper presented at the Proceedings of 2 nd International Conference on Networked Learning, University of Lancaster, 17-19 April.

Wenger, E. (1998) Communities of practice: learning, meaning, and identity (Cambridge, Cambridge University Press). 